\title{
Tendências estruturais do mundo do trabalho no Brasil
}

\author{
Structural trends in the world of work in Brazil
}

Marcio Pochmann (https://orcid.org/0000-0002-3940-1536) ${ }^{1}$

\begin{abstract}
Through a brief historical recovery, the article seeks to describe the main trends in the world of work in Brazil. The emphasis of the article focuses on the current early transition to the service society, whose significant change can be observed in the operation of the labor market itself. Also, it considers the predominance of massive open unemployment, the expansion of the underutilization of the labor force and the generalization of precariousness in professions due to the absence of economic growth and the return of the neoliberal reforms. The result has been the increasing polarization within the world of work. Key words Work, Politics, Society
\end{abstract}

Resumo Através de breve recuperação histórica busca-se descrever as principais tendências do mundo do trabalho no Brasil. A ênfase do ensaio focaliza a atual transição antecipada para a sociedade de serviços, cuja alteração significativa pode ser observada no próprio funcionamento do mercado de trabalho. Também se considera a predominância do massivo desemprego aberto, da ampliação da subutilização da força de trabalho e da generalização da precarização nas ocupações em função da ausência de crescimento econômico $e$ do retorno das reformas neoliberais. O resultado tem sido a polarização crescente no interior do mundo do trabalho.

Palavras-chave Trabalho, Politica, Sociedade
${ }^{1}$ Centro de Estudos Sindicais e de Economia do Trabalho, Instituto de Economia, Universidade Estadual de Campinas. R. Pitágoras, Barão Geraldo. 13083-970 Campinas SP Brasil.

pochmann@unicamp.br 


\section{Introdução}

O mundo do trabalho enquanto percepção do envolvimento distinto dos seres humanos com o conteúdo e relações laborais não se apresenta estável ao longo do tempo. Em geral, tende a sofrer impactos diretos e indiretos das possíveis trajetórias dos sistemas produtivos, bem como do formato pelo qual a regulação se estabelece sobre o funcionamento do mercado de trabalho.

Nesse sentido, a tradicional classificação das atividades produtivas ajuda no entendimento acerca dos dinamismos diferenciados entre os três principais setores econômicos (primário, secundário e terciário). O setor primário se constitui pelas atividades da agropecuária e o setor secundário compreende a indústria de transformação e construção civil, enquanto o setor terciário responde pelas atividades de serviços, como no caso dos complexos da saúde, educação e outros.

Até pouco tempo, o setor terciário era pouco estudado, pois englobava o conjunto de atividades econômicas que não faziam parte dos setores primário e secundário. Mas diante da tendência de terciarização dos sistemas produtivos, sobretudo após a segunda metate do século passado, os serviços emergiram com papel de destaque crescente.

No passado das sociedades agrária, urbana e industrial, os serviços eram geralmente considerados estáveis, pois responsáveis por irrisórios ganhos de produtividade diante de intensa agregação de trabalhadores. Mais recentemente, contudo, o setor terciário passou a assumir inédito protagonismo com os estudos que buscaram analisar a incorporação do progresso tecnológico, a expansão das ocupações e a crescente importância relativa no produto nos países diante da constituição da nova sociedade de serviços.

É para tratar das diferentes temporalidades na evolução da composição ocupacional brasileira que o presente ensaio analisa as tendências estruturais gerais do mundo do trabalho, é para além das especificidades atinentes aos diferentes setores que o compõem, como no caso do complexo da saúde. Considera o conjunto de dados oficiais, do primeiro Censo Demográfico, realizado no país no ano de 1872 aos dias de hoje, com base nas pesquisas realizadas pelo IBGE para sustentar as prinicpais transfromações ocorridas no mercado de trabalho.

A primeira parte, nesse sentido, apresenta uma breve recuperação histórica acerca das temporalidades identificadas no mundo do trabalho brasileiro. Na sequência, busca-se descrever os principais efeitos da atual transição antecipada para a sociedade de serviços no mundo do trabalho. Na terceira e última parte, considera-se o comportamento mais recente do mercado de trabalho diante das reformas neoliberais implementadas de desde o ano de 2016.

\section{Mundo o trabalho em três tempos}

Nos últimos duzentos anos, o mundo do trabalho no Brasil percorreu três temporalidades completamente distintas, porém complementares e articuladas entre si. A sua breve recuperação histórica permite identificar o sentido geral das mudanças pelas quais a classe trabalhadora foi sendo submetida desde a consolidação do sistema capitalista na condição de país periférico e, por consequência, dependente do centro dinâmico mundial.

A primeira temporalidade respondeu à longeva sociedade agrária que terminou por estabelecer as bases pelas quais o mercado de trabalho se constituiu demarcado por importantes especificidades em relação a outros países. A tardia transição e a consolidação do modo de produção capitalista no Brasil, somente ao final do século XIX, estabeleceram traços marcantes da formação e desenvolvimento do mercado de trabalho disperso regionalmente num país de dimensão continental liderado por elites autoritárias e de forte e longeva herança escravista.

A segunda temporalidade do mundo do trabalho atendeu aos requisitos da transição para a sociedade urbana e industrial caracterizada por rápido e intenso processo capitalista de modernização conservadora entre as décadas de 1930 e 1980. Sem ter experimentado qualquer possibilidade de reformas clássicas do capitalismo contemporâneo, tais como a fundiária, tributária e social, a conformação do mercado nacional de trabalho terminou reproduzindo profunda heterogeneidade ocupacional e ampla exclusão social tradicional do subdesenvolvimento periférico no capitalismo mundial.

Por fim, a terceira temporalidade do mundo do trabalho, atualmente em curso neste início do século XXI, com a antecipada passagem da incompleta sociedade urbana e industrial para a de serviços. Decorrente do precoce processo de desindustrialização que acompanha o país desde a inserção passiva e subordinada desencadeada na década de 1990 por governos neoliberais, o funcionamento do mercado de trabalho tem convergido para a generalização de condições extrema- 
mente regressivas associadas ao relativo declínio de ocupações intermediárias e generalização do emprego na base da pirâmide social, o que favorece o aprofundamento da polarização social.

\section{O mundo do trabalho na sociedade agrária}

O ingresso no modo de produção capitalista no Brasil remonta ao conjunto de decisões do período imperial (1822-1889), como a definição do direito de propriedade privada instituído em 1850, com a Lei das Terras ${ }^{1}$, e as várias medidas gradualistas de transição do trabalho escravo para o mercado livre de trabalho a partir dos anos de 1830, com a regulação de contratos de trabalho aos estrangeiros. Por conta disso, a formação do mercado de trabalho contemplou especificidades fundamentais que o tornaram mais complexo e diferenciado regionalmente.

A começar pela constituição do mundo do trabalho assentado em três componentes sociais distintos. De um lado, a massa de negros africanos trazida pelo tráfico de escravos, cujo conservadorismo imposto pela elite escravocrata na passagem para o trabalho livre resultou do projeto de branqueamento do final do século XIX, capaz de postergar a inclusão dos ex-escravos no mercado nacional de trabalho.

De outro, a força social representada pela imigração branca que constituiu inicialmente parte importante do mercado de trabalho, especialmente nas atividades mais dinâmicas da época no país (cafeicultura na região sudeste). E, ainda, conta também a presença de segmentos livres remanescentes de mestiços pobres e negros libertos e fugidos, quase como acessória à escravidão, pois com ingresso restrito às ocupações, quase sempre em atividades residuais e de contido rendimento no interior do mercado de trabalho.

Dessa configuração do mundo do trabalho decorrente da transição para o capitalismo durante a sociedade agrária, destaca-se a preocupação patronal com a disciplina para o exercício do trabalho livre, pressupondo a expropriação como mecanismo de transformação dos indivíduos em proletários. Nesse sentido, a legislação do trabalho desde o século XIX mostrou ser fundamental o estabelecimento dos mecanismos fundantes da disciplina patronal ao exercício laboral do emprego regular da mão de obra.

A despeito da emergência do Estado liberal na República Velha (1889-1930), mínima em termos de ação possível no interior do mercado de trabalho em formação, destaca-se legislação voltada à repressão e imposição de penalidade para as situações consideradas de vadiagem e vagabundagem. Uma diversidade de leis associadas à locação de serviço orientou a imposição da disciplina laboral (coação ao trabalho em qualquer ocupação de caráter regular) para garantir a transformação dos indivíduos (ex-escravo, imigrante estrangeiro e trabalhador livre nacional) em proletários disponíveis à demanda do capital.

Exemplo disso pode ser notado já em 1830 com a implantação do Código Criminal sobre a repressão da vadiagem ${ }^{2}$ e mendicância, assim como em 1837, com a lei da contratação de trabalho estrangeiro ${ }^{3}$ e, em 1850, com as regras de prestação de serviços estabelecidas pelo Código Comercial $^{4}$. Também faz referência aos interesses patronais na fixação da disciplina laboral, a legislação de 1879 que tratou da imigração subsidiada como base do sistema de colonato.

Com a instalação da República (1889), o arsenal das legislações anteriores sobre a locação de serviços agrícolas foi revogado em virtude da dominância da lógica liberal e o entendimento de que contrariava a liberdade individual, comprometendo a atração dos fluxos imigratórios de mão de obra branca. Em função disso que a quase ausência da legislação laboral se justificaria pelo risco da regulação pública das relações de trabalho impedir o controle privado e o exercício da disciplina laboral (Tabela 1).

Assim, a omissão do Estado liberal permitiu que durante a República Velha, o funcionamento selvagem do mercado de trabalho estivesse amplamente favorável aos interesses do patronato no Brasil. Com o predomínio da sociedade agrária, as condições de usos e remuneração da força de trabalho, imediatamente após a abolição da escravidão, seguiram próximas do regime de quase servidão.

De acordo com as informações oficiais disponíveis, a evolução do mundo do trabalho se apresentou fortemente dependente das ocupações na agropecuária, dispersas no território nacional. Ainda que entre 1872 e 1940, a sociedade agrária tenha registrado sinais de declínio, a agropecuária se manteve como responsável por absorver cerca de dois terços do total das ocupações abertas no país, enquanto os postos de trabalhos urbanos apresentaram ritmo de crescimento superior nos setores secundário e terciário, o que permitiu passar de 22,5\% para 31,2\% da População Economicamente Ativa (PEA). 
Tabela 1. Brasil - Evolução da população total, ocupada e desocupada em 1872 e 1940.

\begin{tabular}{lrrrc}
\hline \multicolumn{1}{c}{ Itens } & $\begin{array}{c}\mathbf{1 8 7 2} \\
(\mathbf{e m ~} \text { mil) }\end{array}$ & $\begin{array}{c}\mathbf{1 9 4 0} \\
(\mathbf{e m ~} \text { mil) }\end{array}$ & $\begin{array}{c}\text { Variação absoluta } \\
\text { anual (em mil) }\end{array}$ & $\begin{array}{c}\text { Variação relativa } \\
\text { anual (em \%) }\end{array}$ \\
\hline População Total & 10.112 & 41.165 & 457 & 2,1 \\
PEA & $6.198(100 \%)$ & $15.751(100 \%)$ & 140 & 1,4 \\
PEA ocupada & $5.908(95,3 \%)$ & $14.759(93,7 \%)$ & 130 & 1,4 \\
$\quad$ Primário & $4.506(72,7 \%)$ & $9.844(62,5 \%)$ & 78 & 1,1 \\
Secundário & $282(4,5 \%)$ & $1.880(11,9 \%)$ & 23 & 2,8 \\
$\quad$ Terciário & $1.120(18,1 \%)$ & $3.035(19,3 \%)$ & 29 & 1,5 \\
PEA desocupada & $290(4,7 \%)$ & $992(6,3 \%)$ & 10 & 1,8 \\
\hline
\end{tabular}

Fonte: IBGE ${ }^{5,6}$ (elaboração própria).

\section{O mundo do trabalho na sociedade urbana e industrial}

A transição para a sociedade urbana e industrial sofreu importante impulso com a Revolução de 1930, capaz de abortar o curso do Estado liberal instalado na República Velha e estabelecer as bases do desenvolvimento nacional assentado na consolidação e expansão do mercado interno do país. Para tanto, a constituição do Estado moderno com capacidade para guiar o projeto de urbanização e industrialização passou, inclusive, pela implantação do sistema público das relações de trabalho fundado na organização corporativa da sociedade enquanto elemento estruturante do próprio mercado nacional de trabalho.

Até então, os ciclos econômicos experimentados pela antiga e longeva sociedade agrária havia definido no território nacional uma espécie de arquipélago de enclaves produtivos, responsáveis pela existência de esparsos mercados regionais de trabalho. Apesar de sua concentração nas regiões centro-sul e litorâneas em algumas capitais do Nordeste, o desenvolvimento urbano e industrial compreendeu cerca de cinco décadas de estruturação do mercado de trabalho assentado na centralidade do emprego assalariado, especialmente com carteira assinada.

O movimento de regulação do mercado nacional de trabalho desencadeado a partir da década de 1930, com a implementação da Consolidação das Leis do Trabalho (CLT) ${ }^{7}$ em 1943, durante o Estado Novo (1937-1943), mostrou ser fundamental para a disseminação do regime do salariado, especialmente através emprego formal (com carteira de trabalho assinada). Por força disso, o mundo do trabalho se transformou profundamente no Brasil em apenas cinco décadas.

Pela via da urbanização e industrialização, o emprego nas cidades foi o que mais cresceu, respondendo por quase $70 \%$ do total das ocupações abertas entre os anos de 1940 e 1980. O ritmo de expansão de todos os postos de trabalho equivaleu ao crescimento da própria PEA, o que permitiu tornar o funcionamento do mercado de trabalho próximo do pleno emprego da mão-de -obra, com baixo desemprego aberto (Tabela 2).

Mas isso não significou ausência da precarização e outros males do subdesenvolvimento, como o baixo rendimento, a informalidade e a ampla presença das ocupações não assalariadas, cuja taxa de precarização (soma das ocupações de assalariamento informal, conta própria e sem remuneração em relação ao total da PEA ocupada) reduziu-se significativamente no período de tempo considerado (de $85 \%$ para $45 \%$ da PEA). A expansão da taxa de assalariamento (emprego assalariado em relação ao total dos ocupados), que passou de $45 \%$ para 65\% entre 1940 e 1980 , foi significativa (75\% das ocupações abertas no período foram assalariadas), ainda que 1/3 dos ocupados permanecessem distantes da submissão ao regime do salariado em 1980 (Tabela 3).

A formalização do emprego assalariado foi outro aspecto importante do movimento de estruturação do mercado de trabalho. Em 1980, por exemplo, o emprego assalariado formal representou quase $51 \%$ do total dos ocupados, ao passo que em 1940 não atingia, nem mesmo, a $13 \%$ do total das ocupações no país.

Mesmo que tenha sido reduzido significativamente, constata-se que ainda em 1980, mais de $35 \%$ dos assalariados não tinham contrato formal de trabalho. Em 1940, quase 72\% dos empregados assalariados eram informais.

Diante disso, percebe-se como a implantação da legislação social e trabalhista, com forte amparo no padrão corporativo de relações de trabalho, contribuiu para estruturação do mercado de trabalho durante a constituição da sociedade 
Tabela 2. Brasil - Evolução da população total, ocupada e desocupada em 1940 e 1980.

\begin{tabular}{lrrcc}
\hline \multicolumn{1}{c}{ Itens } & $\begin{array}{c}\mathbf{1 9 4 0} \\
(\mathbf{e m ~} \mathbf{~ m i l )}\end{array}$ & $\begin{array}{c}\mathbf{1 9 8 0} \\
(\mathbf{e m ~} \mathbf{~ m i l )}\end{array}$ & $\begin{array}{c}\text { Variação absoluta } \\
\text { anual (em mil) }\end{array}$ & $\begin{array}{c}\text { Variação relativa } \\
\text { anual (em \%) }\end{array}$ \\
\hline População Total & 41.165 & 119.002 & 1.946 & 2,7 \\
PEA & $15.751(100 \%)$ & $43.236(100 \%)$ & 689 & 2,6 \\
PEA ocupada & $14.759(93,7 \%)$ & $42.026(97,2 \%)$ & 683 & 2,6 \\
$\quad$ Primário & $9.844(62,5 \%)$ & $12.997(30,1 \%)$ & 79 & 0,7 \\
Secundário & $1.880(11,9 \%)$ & $12.042(27,8 \%)$ & 254 & 4,7 \\
$\quad$ Terciário & $3.035(19,3 \%)$ & $16.987(39,3 \%)$ & 350 & 4,4 \\
PEA desocupada & $992(6,3 \%)$ & $1.210(2,8 \%)$ & 6 & 0,5 \\
\hline
\end{tabular}

Fonte: IBGE $^{6-8}$ (elaboração própria).

Tabela 3. Brasil - Evolução da população por tipo de ocupação e taxa de precarização em 1940 e 1980.

\begin{tabular}{lrrrc}
\hline \multicolumn{1}{c}{ Itens } & $\begin{array}{c}\mathbf{1 9 4 0} \\
(\mathbf{e m ~ m i l )}\end{array}$ & $\begin{array}{c}\mathbf{1 9 8 0} \\
(\mathbf{e m ~ m i l )}\end{array}$ & $\begin{array}{c}\text { Variação absoluta } \\
\text { anual (em mil) }\end{array}$ & $\begin{array}{c}\text { Variação relativa } \\
\text { anual (em \%) }\end{array}$ \\
\hline PEA ocupada & $14.759(100 \%)$ & $42.026(100 \%)$ & 683 & 2,6 \\
Empregador & $362(2,4 \%)$ & $1.340(3,2 \%)$ & 25 & 3,3 \\
Assalariado & $6.615(44,8 \%)$ & $27.152(64,6 \%)$ & 513 & 3,6 \\
$\quad$ Formal & $1.906(12,9 \%)$ & $21.272(50,6 \%)$ & 484 & 6,2 \\
$\quad$ Informal & $4.709(31,9 \%)$ & $5.880(14,0 \%)$ & 29 & 0,6 \\
Conta própria & $4.694(31,8 \%)$ & $9.555(22,7 \%)$ & 122 & 1,8 \\
Sem remuneração & $3.088(20,9 \%)$ & $3.978(9,5 \%)$ & 23 & 0,6 \\
Precarização* & $12.491(84,6 \%)$ & $19.413(46,2 \%)$ & 174 & 1,1 \\
\hline
\end{tabular}

Fonte: $\mathrm{IBGE}^{6-8}$ (elaboração própria) * Soma das ocupações de assalariamento informal, conta própria e sem remuneração em relação ao total da PEA ocupada.

urbana e industrial. Nesse sentido, a definição do conceito de categoria profissional foi essencial para estabelecer a organização e o financiamento dos sindicatos, os acordos e negociações coletivas de trabalho e a atuação da justiça do trabalho.

Nas décadas de 1930 e 1950, por exemplo, a legislação social e trabalhista centrada na atuação importante do Estado (Ministério do Trabalho e Justiça Trabalhista) focou fundamentalmente o mundo do trabalho urbano frente à reiterada resistência do patronato rural à qualquer forma de regulação pública do trabalho. Somente a partir da aprovação do Estatuto do Trabalhador', na década de 1960, quando a população agrária deixou de ser dominante na população nacional, que, lenta e gradualmente, as ocupações do meio rural foram sendo incorporadas ao sistema público nacional de relações de trabalho.

\section{O mundo do trabalho na sociedade de serviços}

O decréscimo relativo nas ocupações agrárias em simultânea expansão dos postos de tra- balhos urbanos (indústria e serviços) apontou para a formação de ampla classe trabalhadora e significativa classe média social entre as décadas de 1930 e 1940. A estrutura de classe e frações de classes sociais estabelecida por força de intensa expansão econômica nacional que permitia constituir a sociedade urbana e industrial passou a ser profundamente modificada a partir da década de 1980, com crise da dívida externa e a adoção - pela primeira vez desde a década de 1930 - das políticas recessivas no último governo da Ditadura civil-militar (1964-1985).

Com isso, o projeto de urbanização e industrialização em curso desde a década de 1930 começou a perder a centralidade no Estado desenvolvimentista. A herança da dívida externa, da superinflação, do endividamento público, do rentismo, da pobreza e da desigualdade deixada pelo autoritarismo comprometeu significativamente parte importante das políticas econômica e social do período democrático, implicando perda de vários anos para superação de alguns deles (a superinflação em 1994 e a dívida externa em 2008), começar a resolver outros (a pobreza e de- 
sigualdade nos anos 2000) e aqueles, ainda, sem resolução (a dívida pública e o rentismo).

Além disso, a adoção do receituário neoliberal nos anos de 1990 coincidiu com o ingresso passivo e subordinado do Brasil na globalização comandada por grandes corporações transnacionais. Desde então, o país precocemente ingressou no processo de desindustrialização, pois sem universalizar o padrão de consumo a todos os brasileiros, sobretudo na base da pirâmide social, vem declinando a capacidade de produção manufatureira.

Nos países com processo de desindustrialização madura, a diminuição relativa da participação da manufatura no ciclo produtivo transcorreu após a totalidade da população ter sido incluída no padrão de consumo da sociedade urbana e industrial, coincidindo com a maior expansão do setor terciário na economia. Nesse sentido, os serviços mais dinâmicos tenderam a ser aqueles vinculados à produção e logística, entre outros, mais associados ao emprego de mão de obra com maiores requisitos de formação e remuneração.

Em sendo necessário, as importações de bens industriais podem complementar pontualmente as exigências do consumo interno, uma vez que se tratam, em geral, da reposição de produtos pela população ou de alguma novidade. Isso parece ser irrealizável em países de desindustrialização precoce como no Brasil devido à expressiva dimensão populacional excluída do acesso aos bens industriais, cuja escala de importação de manufaturados torna-se difícil de ser compensada por bens não industriais.

Além disso, o declínio relativo dos bens industriais na produção não se deveu tanto ao maior ritmo de crescimento do setor terciário, mas a decadência da produção manufatureira, com o encolhimento de alguns ramos e o desaparecimento de outros. Por força disso, a antecipação da passagem para a sociedade de serviços decorre mais do inchamento do setor terciário da economia em virtude do vácuo deixado pela precoce desindustrialização.

Assim, o processo de terciarização da economia brasileira tem sido caracterizado pela especificidade da continuidade na queda absoluta das ocupações na agropecuária e da recente queda relativa dos postos de trabalho na manufatura. Em quase quarenta anos, a participação do setor terciário no total da PEA aumentou $59,5 \%$, pois saltou de menos de $40 \%$, em 1980 , para $62,7 \%$, em 2018. No mesmo período de tempo, o setor primário registrou a queda de $73,4 \%$ na partici- pação relativa no total da PEA, com a diminuição de cerca de 13 milhões para 8,5 milhões de ocupados (Tabela 4).

O setor secundário registrou redução na participação relativa no total da PEA de $36,2 \%$, pois declinou de $27,8 \%$ para $17,7 \%$, entre 1980 e 2018. Nesse período, contudo, a quantidade de ocupados no setor secundário cresceu $1,1 \%$ em média ao ano, enquanto a média anual foi de $2,1 \%$ para a expansão da PEA ocupada e de 3,6\% no caso das ocupações do setor terciário.

Simultaneamente, a taxa nacional de desemprego elevou-se significativamente. Entre 1980 e 2018, a quantidade de desempregados foi multiplicada por 10 vezes, fazendo subir a taxa de desocupação de menos de $3 \%$ para quase $12 \%$ da PEA.

Coincidindo com a elevação do desemprego nacional, percebe-se o aumento da precarização entre os ocupados. Dos 19,4 milhões de trabalhadores expostos às condições de trabalho precários em 1980, o Brasil registrou, em 2018, a quantia de 44,5 milhões de ocupados em ocupações precárias, cuja expansão média anual foi levemente superior $(2,2 \%)$ à própria geração dos postos de trabalho no Brasil (2,1\%). Ainda em relação aos ocupados, nota-se relativa estabilização na taxa de assalariamento, uma vez que a sua expansão transcorreu no mesmo ritmo da abertura de postos de trabalho (Tabela 5).

Para, além disso, constata-se que os empregos assalariados que mais cresceram foram a dos trabalhos informais, cuja participação relativa na PEA ocupada passou de $14 \%$, em 1980, para quase $20 \%$, em 2018. A contrapartida disso foi o decrescimento do peso relativo do emprego formal de $78,3 \%$ do total dos assalariados para $70,4 \%$ no mesmo período de tempo.

Com a estabilização relativa na taxa de assalariamento, as ocupações que mais cresceram em relação ao total de postos de trabalho abertos no país durante o período foram as de empregador $(52,1 \%)$ e de conta própria $(12,8 \%)$. Por força disso que a recente e antecipada transição para a sociedade de serviços no Brasil tem sido marcada pela desestruturação do mercado de trabalho, com significativa presença do desemprego aberto, a subutilização dos trabalhadores e a precarização das ocupações geradas.

$\mathrm{Na}$ sociedade urbana e industrial, com o decréscimo da participação relativa do setor primário e ascensão dos setores secundário e terciário, os serviços foram, em 1980, o principal empregador de força de trabalho no Brasil. Em comparação com o ano de 1940, por exemplo, 
Tabela 4. Brasil - Evolução da população total, ocupada e desocupada em 1980 e 2018.

\begin{tabular}{lrccc}
\hline \multicolumn{1}{c}{ Itens } & $\begin{array}{c}\mathbf{1 9 8 0} \\
(\mathbf{e m ~} \mathbf{~ m i l})\end{array}$ & $\begin{array}{c}\mathbf{2 0 1 8} \\
(\mathbf{e m ~} \mathbf{~ m i l )}\end{array}$ & $\begin{array}{c}\text { Variação absoluta } \\
\text { anual (em mil) }\end{array}$ & $\begin{array}{c}\text { Variação relativa } \\
\text { anual (em \%) }\end{array}$ \\
\hline População Total & 119.002 & 208.495 & 2.355 & 1,5 \\
PEA & $43.236(100 \%)$ & $105.197(100 \%)$ & 1.631 & 2,4 \\
PEA ocupada & $42.026(97,2 \%)$ & $93.002(88,4 \%)$ & 1.342 & 2,1 \\
$\quad$ Primário & $12.997(30,1 \%)$ & $8.455(8,0 \% \%)$ & -119 & $-0,8$ \\
Secundário & $12.042(27,8 \%)$ & $18.622(17,7 \%)$ & 173 & 1,1 \\
$\quad$ Terciário & $16.987(39,3 \%)$ & $65.925(62,7 \%)$ & 1.288 & 3,6 \\
PEA desocupada & $1.210(2,8 \%)$ & $12.195(11,6 \%)$ & 289 & 6,3 \\
\hline
\end{tabular}

Fonte: $\mathrm{IBGE}^{8-10}$ (elaboração própria).

Tabela 5. Brasil - Evolução da população por tipo de ocupação e taxa de precarização em 1980 e 2018.

\begin{tabular}{lrrcc}
\hline \multicolumn{1}{c}{ Itens } & $\begin{array}{c}\mathbf{1 9 8 0} \\
\mathbf{( e m} \text { mil) }\end{array}$ & $\begin{array}{c}\mathbf{2 0 1 8} \\
(\mathbf{e m ~ m i l )}\end{array}$ & $\begin{array}{c}\text { Variação absoluta } \\
\text { anual (em mil) }\end{array}$ & $\begin{array}{c}\text { Variação relativa } \\
\text { anual (em \%) }\end{array}$ \\
\hline População Total & 119.002 & 208.495 & 2.355 & 1,5 \\
PEA & $43.236(100 \%)$ & $105.197(100 \%)$ & 1.631 & 2,4 \\
PEA desocupada & $1.210(2,8 \%)$ & $12.195(11,6 \%)$ & 289 & 6,3 \\
PEA ocupada & $42.026(100 \%)$ & $93.002(100 \%)$ & 1.342 & 2,1 \\
Empregador & $1.340(3,2 \%)$ & $4.532(4,9 \%)$ & 84 & 3,3 \\
Assalariado & $27.152(64,6 \%)$ & $62.447(67,1 \%)$ & 929 & 2,2 \\
$\quad$ Formal & $21.272(50,6 \%)$ & $43.940(47,2 \%)$ & 596 & 1,9 \\
$\quad$ Informal & $5.880(14,0 \%)$ & $18.507(19,9 \%)$ & 332 & 3,1 \\
Conta própria & $9.555(22,7 \%)$ & $23.848(25,6 \%)$ & 376 & 2,5 \\
Sem remuneração & $3.978(9,5 \%)$ & $2.175(2,4 \%)$ & -47 & $-0,5$ \\
Precarização & $19.413(46,2 \%)$ & $44.530(47,9 \%)$ & 661 & 2,2 \\
\hline
\end{tabular}

Fonte: $\mathrm{IBGE}^{8-10}$ (elaboração própria).

a composição do setor de serviços tinha sofrido modificações importantes registradas em 1980 e ainda maiores em 2018.

De um lado, a diminuição de importância relativa das ocupações totais nos segmentos dos Serviços de Distribuição (comércio, comunicação, transporte e outros) em 5,6\% e dos Serviços Pessoais (doméstico, segurança, cuidadores e outros) em 22,2\% entre 1940 e 1980 . De outro, o avanço na participação relativa no total das ocupações nos Serviços Sociais (saúde, educação, assistência e outros) em 29,7\% e nos Serviços de Produção (engenharia, tecnologia, propaganda e outros) em $56,1 \%$ no mesmo período de tempo.

De maneira geral, o ciclo da industrialização e urbanização nacional representou a transformação da força de trabalho alocada em setores de menor produtividade e remuneração para os de maior produtividade e rendimento do trabalho. Isso porque houve deslocamento de trabalhadores do meio rural, ocupados na própria subsis- tência, para as atividades urbanas na construção civil, indústria de transformação, comércio e serviços. No interior do setor de serviços, constatouse o deslocamento das ocupações mais simples e de contida produtividade como nos serviços pessoais (trabalho doméstico e outros) para os serviços sociais e de produção.

$\mathrm{Na}$ transição atual para a sociedade de serviços, percebe-se, contudo, que não parece haver evidências precisas que o mesmo sentido do deslocamento de atividades de menor para maior produtividade e remuneração, registrado na sociedade urbana e industrial, esteja ocorrendo. Pelo contrário, as informações oficiais existentes apontam para o sentido inverso, ou seja, a destruição de atividades e ocupações situadas nos segmentos de maior produtividade e remuneração e a expansão dos postos de trabalho de menor produtividade e rendimento.

Na comparação entre os anos de 1980 e 2018, nota-se, por exemplo, que o segmento que perdeu 
posição relativa no total da ocupação foi o Serviço de Produção em 46,9\%, enquanto os Serviços Sociais mantiveram-se relativamente estabilizados $(0,7 \%)$. Ao mesmo tempo, os segmentos que conseguiram elevar a participação relativa no total da ocupação foram os Serviços de Distribuição $(6,2 \%)$ e os Serviços Pessoais (1,3\%).

Todas essas modificações estruturais no funcionamento do mercado nacional de trabalho seguiram sendo realizadas sem alterações substanciais no sistema público de relações de trabalho. Com a transição do autoritarismo para o regime democrático e a implantação da Constituição Federal de $1988^{11}$, prevaleceu o padrão corporativo de organização do mundo do trabalho, com o reforço na adoção de políticas públicas para o assalariamento formal e o afrouxamento de certos mecanismos repressivos estabelecidos no âmbito da CLT.

Na década de 1990, contudo, a experiência da flexibilização na legislação social e trabalhista permitiu certa diversificação nas formas de contratação do trabalho assalariado, com a legitimação e difusão da terceirização nas atividades meio das ocupações nas empresas. Nesse sentido, as funções como de segurança, alimentação, manutenção, transporte, limpeza e outras, em geral de baixa remuneração, foram deslocadas para o emprego terceirizado tanto no setor público como privado.

Ao mesmo tempo, a aprovação governamental de medida fiscal voltada para a isenção de tributos a lucros e dividendos na metade da década de 1990 favoreceu a expansão do trabalho na condição do regime de Pessoa Jurídica (PJ, empregador de si próprio), em detrimento dos empregos assalariados de alta remuneração nas empresas. Posteriormente, nos anos 2000, uma diversidade de políticas públicas orientadas às micro e pequenas empresas permitiu constituir a forma do Micro Empreendedor Individual (MEI) na perspectiva de formalização das ocupações por conta própria, assim como na contratação de trabalhadores domésticos.

Somente a partir de 2016 que, diante da mais grave recessão econômica do capitalismo brasileiro, um conjunto de mudanças substanciais na legislação social e trabalhista foi introduzido com o objetivo governamental de rompimento com o sistema público de relações de trabalho. Medidas como a legislação que universalizou a terceirização dos contratos de trabalho, além da reforma trabalhista, da Emenda Constitucional $95^{12}$ e das propostas de reformulação do sistema público de aposentadoria e pensão em curso, apontam para o aprofundamento da desestruturação do funcionamento do mercado de trabalho brasileiro e a ascensão do sistema privado de relações entre o capital e o trabalho (contratualismo individual).

Em plena transição antecipada para a sociedade de serviços, os movimentos de desestruturação do mercado de trabalho e de rompimento com o padrão corporativo de organização social implicam aprofundar a polarização no interior do mundo do trabalho. Isso porque a destruição das ocupações de classe média tem sido acompanhada da massificação do desemprego estrutural e da precarização das ocupações assentadas na instabilidade contratual, escassez dos direitos sociais e trabalhistas e contida remuneração.

\section{A terciarização no mundo do trabalho}

O funcionamento do mercado de trabalho no longo prazo apresentou duas trajetórias distintas no Brasil ${ }^{13}$. A primeira refere-se tanto à diminuição relativa contínua do trabalho no setor primário na economia nacional desde a década de 1870 , como a expansão relativa e absoluta dos postos de trabalho nos setores secundário e terciário no período que compreende os anos de 1872 e 1980.

A segunda trajetória do funcionamento do mercado de trabalho caracteriza-se pela queda relativa dos postos de trabalho no setor secundário a partir da década de 1980 em simultâneo decréscimo absoluto das ocupações no setor primário e elevação relativa e absoluta do emprego no setor terciário. Com isso, percebe-se que, em 2018, por exemplo, a participação relativa do setor terciário no total da ocupação aproximou-se da verificada no setor primário em 1872, quando a escravidão ainda predominava no país.

Diante disso, cabe considerar o quanto as transformações no mundo do trabalho durante as últimas três décadas levaram o setor terciário a predominar no conjunto das ocupações ${ }^{14}$. Com a terciarização ocupacional, verifica-se a tendência de concentração dos postos de trabalho na base da pirâmide social e redução relativa dos empregos assalariados de classe média.

No ano de 2016, por exemplo, quase $71 \%$ das ocupações no Brasil recebiam até 2 salário mínimos mensais, enquanto em 1986 eram de 68,1\%. Ou seja, o crescimento de $3,8 \%$ na proporção das ocupações de até 2 salários mínimos no total dos trabalhadores brasileiros.

Em compensação, o segmento das ocupações com rendimentos intermediários, entre 2,1 a 5 salários mínimos mensais, decresceu em 3,6\% em relação ao total dos trabalhadores, pois decaiu de 
$22 \%$ para $21,2 \%$, entre 1986 e 2018. Também o segmento de maior rendimento, acima de cinco salários mínimos mensais, diminuiu em 19,2\% a sua participação relativa no total das ocupações, passando de $9,9 \%$ para $8 \%$ no mesmo período de tempo.

Pode-se compreender o achatamento na distribuição dos rendimentos entre os ocupados como resultado da expansão do setor terciário e do decréscimo dos setores primário e secundário. Enquanto a participação relativa dos ocupados nos serviços aumentou 40,6\%, entre 1986 e 2018, diminuiu a proporção dos postos de trabalho tanto no setor primário $(36,8 \%)$ como no setor secundário $(26,5 \%)$ no total dos trabalhadores.

O deslocamento das ocupações nos setores primário e secundário para o setor de serviços também não deixa de revelar o avanço da modalidade de contratação menos associada ao emprego salarial, cuja taxa de assalariamento manteve-se estabilizada em $67 \%$ dos ocupados nas três últimas décadas. Entre os anos de 1986 e 2018, por exemplo, a formalização do empregado assalariado cresceu $5 \%$, ao passo que a ocupação de conta própria subiu $11,2 \%$.

No sentido inverso, a participação relativa dos ocupados sem remuneração, empregador e emprego informal teria sido reduzida entre os anos de 1986 e 2016. A diminuição mais expressiva na participação relativa transcorreu nas ocupações sem remuneração $(-49,8 \%)$, seguidas do emprego informal $(-13,1 \%)$ e de empregador $(-5,15)$.

Diante do movimento de predominância da terciarização do mundo do trabalho, com concentração das ocupações geradas, cada vez mais, na base da pirâmide social, os jovens foram os que mais terminaram sendo afetados negativamente pela contração de sua participação relativa no total dos trabalhadores. Em 1986, por exemplo, decaiu o peso relativo da faixa etária de 16 a 24 anos no total das ocupações em 41,8.

Por outro lado, o segmento etário de 25 a 59 anos aumentou a sua posição relativa no total da ocupação em 9,2\%. Também a parcela da População Economicamente Ativa ocupada com 60 anos e mais de idade cresceu a sua presença relativa no total da ocupação em $82 \%$.

No ano de 1986, por exemplo, para uma vaga ocupada por trabalhador de 60 anos e mais de idade tinha um conjunto de cinco jovens trabalhando. Trinta anos depois, em 2018, a cada ocupação preenchida por trabalhador de 60 anos e mais de idade, havia somente 1,5 jovem trabalhado.

\section{Reformas neoliberais recentes e comportamento do mercado de trabalho}

Diante da mais grave crise do capitalismo brasileiro transcorrida em simultânea compressão do regime democrático desde o final de 2014, quando parte da oposição partidária derrotada não mais aceitou o resultado da eleição presidencial, um conjunto importante de medidas desregulatórias do mercado de trabalho foi sendo rapidamente implementado. $\mathrm{O}$ resultado disso tem sido o aprofundamento do sentido geral da desestruturação do mercado de trabalho que já se encontrava em curso mediante a desindustrialização precoce e transição antecipada para a sociedade de serviços.

Apesar do discurso patronal de incentivo à redução do custo do trabalho e à flexibilização contratual, enquanto argumento decisivo para a geração de novos postos de trabalho, o nível geral do emprego assalariado não retornou. Tampouco, a formalização dos contratos de trabalho foi garantida, transcorrendo justamente o contrário no período recente.

Comparando-se o custo do trabalho médio na indústria brasileira com o dos Estados Unidos e o da China, nota-se uma recente trajetória pronunciada de queda. Em 2014, por exemplo, o custo do trabalho na indústria brasileira era 2,6 vezes maior que o da China e quase $30 \%$ do verificado nos EUA.

Com a recente recessão econômica e medidas desregulatórias do mercado de trabalho adotadas pelos governos brasileiros, o custo do trabalho na indústria chinesa passou a ser $16 \%$ superior a do Brasil, em 2016, e 26\% menor ao registrado nos Estados Unidos em 2015.

No mesmo sentido, pode-se perceber como a reforma trabalhista introduzida desde o final de 2017 tem favorecido o deslocamento do emprego assalariado formal para o contrato informal e ocupações por conta própria. Todas essas formas de trabalho transcorrem à margem da regulação, sem proteção social e trabalhista, ademais da decrescente contribuição para o sistema público de aposentadoria e pensão.

Acompanhando a evolução recente das ocupações assalariadas informais, constata-se o crescimento de quase $12 \%$ entre os anos de 2014 e 2018. No mesmo período de tempo, o emprego assalariado formal sofreu redução de 9,5\%.

Da mesma forma pode-se constatar a elevação das ocupações por conta própria. Entre os anos de 2014 e 2018, por exemplo, o total dos trabalhadores por conta própria aumentou 9,6\%, 
tendo os contratos sem reconhecimento de pessoa jurídica registrada (CNPJ) maior expansão $-10,8 \%$ do que os postos de trabalhos autônomos com CNPJ $(4,8 \%)$.

No sentido geral de avanços nos trabalhos por conta própria e emprego assalariado informal, despossuído do acesso aos direitos sociais e trabalhistas, percebe-se também a expansão recente das taxas de desemprego e de subutilização da mão de obra disponível no mercado de trabalho brasileiro. Tanto a ausência de dinamismo econômico como a desregulação do mercado de trabalho têm sido responsáveis pelo registro das maiores parcelas da força de trabalho distante do acesso ao sistema público de proteção social e trabalhista.

Somente em relação ao avanço do desemprego e à disseminação da mão de obra subutilizada em sua condição de trabalho, o Brasil tem registrado recordes recentes, sem comparação com o passado distante. Diante disso, o saldo das reformas neoliberais, em curso desde o ano de 2016, tem sido ainda mais prejudicial ao comportamento do mercado de trabalho brasileiro.

\section{Considerações finais}

A breve recuperação histórica apresentada anteriormente buscou situar as principais mudanças atualmente em curso no funcionamento do mercado de trabalho brasileiro, como parte intrínseca da transição para a antecipada sociedade de serviços. As alterações substanciais no mundo do trabalho refletem tanto o precoce processo de desindustrialização exposto pela forma com que o Brasil ingressou na globalização capitalista desde os anos de 1990, como a desconstrução mais recente no marco regulatório do mercado de trabalho impostos pelas reformas neoliberais.

O resultado de tudo isso tem sido a predominância de massivo desemprego aberto, acompanhado da ampliação da subutilização da força de trabalho e da generalização da precarização nas ocupações. A polarização crescente no interior da sociedade revela não apenas a destruição dos postos de trabalho de classe média, como a expansão de empregos não assalariados de maior remuneração, sem acesso à proteção social e trabalhista.

A transição antecipada para a sociedade de serviços tem sido acompanhada de transformações substanciais no funcionamento do mercado de trabalho. Em função disso, a temporalidade em curso no mundo do trabalho brasileiro diferencia-se profundamente da observada em períodos anteriores de predominância tanto da sociedade agrária como a urbana e industrial ${ }^{15}$. 


\section{Referências}

1. Brasil. Presidência da República. Casa Civil. Subchefia para Assuntos Administrativos. Lei $n^{\circ}$ 601, de 18 de setembro de 1850. Dispões sobre as terras devolutas do Império. [acessado 2019 Nov 1]. Disponível em: http://www.planalto.gov.br/ccivil_03/LEIS/L06011850.htm

2. Brasil. Presidência da República. Casa Civil. Subchefia para Assuntos Administrativos. Lei de 16 de dezembro de 1830. Manda executar o código criminal. [acessado 2019 Out 1]. Disponível em: http://www.planalto.gov. br/ccivil_03/leis/lim/LIM-16-12-1830.htm

3. Brasil. Senado Federal. Secretária-Geral da Mesa. Secretária de Informação. Lei no 108, de 11 de outubro de 1837. Dando varias providencias sobre os contractos de locação de serviços dos Colonos. [acessado 2019 Out 25]. Disponível em: http://legis.senado.leg.br/norma/ 541072/publicacao/15632760

4. Brasil. Presidência da República. Casa Civil. Subchefia para Assuntos Jurídicos. Lei no 556, de 25 de junho de 1850. Código Comercial. [acessado 2019 Out 20]. Disponível em: http://www.planalto.gov.br/ccivil_03/ leis/10556-1850.htm

5. Instituto Brasileiro de Geografia e Estatística (IBGE). Recenseamento do Brazil em 1872. Disponível em: https://biblioteca.ibge.gov.br/biblioteca-catalogo? id $=225477 \&$ view $=$ detalhes

6. Instituto Brasileiro de Geografia e Estatística (IBGE). Recenseamento geral do Brasil de 1940. [acessado 2019 Out 1]. Disponível em: https://biblioteca.ibge.gov.br/ index.php/biblioteca-catalogo?id $=765 \&$ view $=$ detalhes

7. Brasil. Presidência da República. Casa Civil. Subchefia para Assuntos Jurídicos. Decreto-Lei $n^{\circ} 5.452$, de $1^{\circ}$ de maio de 1943. Aprova a Consolidação das Leis do Trabalho. [acessado 2019 Out 5]. Disponível em: http:// www.planalto.gov.br/ccivil_03/decreto-lei/del5452. htm

8. Instituto Brasileiro de Geografia e Estatística (IBGE). Censo demográfico: 1980. [acessado 2019 Out 1]. Disponível em: https://biblioteca.ibge.gov.br/index.php/ biblioteca-catalogo?id $=772$ \&view $=$ detalhes

9. Instituto Brasileiro de Geografia e Estatística (IBGE). Pesquisa Nacional por Amostra de Domicílios Contínua de 2018. [acessado 2019 Out 15]. Disponível em: https://www.ibge.gov.br/estatisticas/sociais/trabalho 19171-pesquisa-nacional-por-amostra-de-domicilioscontinua-mensal.html
10. Brasil. Presidência da República. Casa Civil. Subchefia para Assuntos Jurídicos. Lei no 4.214, de 2 de março de 1963. Dispõe sobre o "Estatuto de Trabalhador Rural". [acessado 2019 Out 23]. Disponível em: http://www. planalto.gov.br/ccivil_03/leis/1950-1969/L4214.htm

11. Brasil. Constituição da República Federativa do Brasil de 1988. Diário Oficial da União 1988; 5 out.

12. Brasil. Presidência da República. Casa Civil. Subchefia para Assuntos Jurídicos. Emenda Constitucional no 95, de 15 de dezembro de 2016. Altera o Ato das Disposições Constitucionais Transitórias, para instituir o Novo Regime Fiscal, e dá outras providências. Diário Oficial da União 2016; $15 \mathrm{dez}$.

13. Pochmann M. O emprego na globalização. São Paulo: Boitempo; 2001.

14. Pochmann M. O emprego no desenvolvimento da nação. São Paulo: Boitempo; 2008.

15. Pochmann M. A desigualdade hereditária. Ponta Grossa: Editora Uepg; 2017.
Artigo apresentado em 07/04/2019

Aprovado em 20/08/2019

Versão final apresentada em 08/10/2019 
